\title{
Embryotoxicity and teratogenicity of tamarind (Tamarindus indica L.) pulp extract using zebrafish (Danio rerio) embryo toxicity assay
}

\author{
Irish C. Lobitaña1, Rizza Mae E. Virtudazo¹, Ann Marie P. Delfin¹, Jhon Niño B. Apura1, Jay P. Picardal², \\ Jake Joshua C. Garces ${ }^{1,2 *}$ \\ ${ }^{1}$ Research Institute of Tropical Biology and Pharmacological Biotechnology, Cebu Normal University, Osmeña Boulevard, \\ Cebu City, Philippines \\ ${ }^{2}$ Biology Department, School of Sciences, College of Arts and Sciences, Cebu Normal University, Osmeña Boulevard, Cebu \\ City, Philippines
}

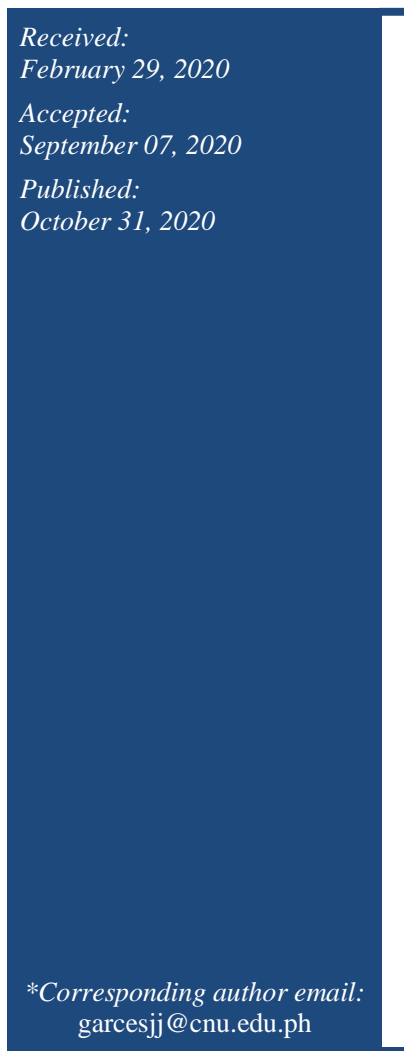

\begin{abstract}
Tamarind is an economically important fruit, widely used in traditional medicine due to its therapeutic properties. However, its bioactive compounds raise an increased precaution on its toxicity. This study investigated the potential embryotoxicity and teratogenicity of Tamarindus indica pulp extracts $(2500 \mathrm{mg} / \mathrm{L}, 1250 \mathrm{mg} / \mathrm{L}, 625 \mathrm{mg} / \mathrm{L}$ and $312.5 \mathrm{mg} / \mathrm{L}$ ) on the eggs and larvae of zebrafish following a Complete Randomized Design (CRD) in equal replications. Morphological assessment of fish larvae was based on total body length (TBL) and trunk tail angle (TTA) at $72 \mathrm{~h}$ post fertilization and were subjected to ANOVA $(\mathrm{p}<0.05)$ and Linear Regression Analysis. Results on the growth parameters (TBL and TTA) showed significant difference among the four treatments in a concentration-dependent manner. At $72 \mathrm{hpf}, 2,500 \mathrm{mg} / \mathrm{L}$ suggests the potential of $T$. indica pulp extract to induce malformations to exposed larvae. This study presents the inverse relationship of $T$. indica pulp extract's embryotoxicity and teratogenicity where larvae mortality occurs in high levels of concentration while malformations form at lower concentrations of $T$. indica pulp extract.
\end{abstract}

Keywords: Embryotoxic, Teratogenic, Tamarindus indica, Zebrafish embryo

How to cite this:

Lobitaña IC, Virtudazo RME, Delfin AMP, Apura JNB, Picardal JP and Garces JJC, 2020. Embryotoxicity and teratogenicity of tamarind (Tamarindus indica L.) pulp extract using zebrafish (Danio rerio) embryo toxicity assay. Asian J. Agric. Biol. 8(4): 457-471. DOI: https://doi.org/10.35495/ajab.2020.02.139

This is an Open Access article distributed under the terms of the Creative Commons Attribution 3.0 License. (https://creativecommons.org/licenses/by/3.0), which permits unrestricted use, distribution, and reproduction in any medium, provided the original work is properly cited.

\section{Introduction}

Plants are an important source of bioactive metabolites and phytochemicals that are used due to their pharmacological and therapeutic properties. Oftentimes, plant components contain active compounds such as tannins, saponins, flavonoids, alkaloids, terpenoids, carotenoids, cardiac glycosides, reducing sugars, steroids, terpenoids, carbohydrates and numerous other derivatives (Mujeeb et al., 2014; Ali et al., 2018). These compounds are being intensively investigated to assess their effects on health, which appear to elicit valuable physiological, behavioral, and immunological effects. Further, most bioactive compounds are reported to possess antibacterial, antioxidant, antifungal, antimicrobial and anti-inflammatory properties (Apu et al., 2013; Andreicut et al., 2018). Thus, the wide utilization of 
plants as a source of pharmaceutical drugs.

As an alternative to primary healthcare, plants with medicinal properties are used to treat injuries, illnesses, or diseases across $80 \%$ of the global population (Akintonwa et al., 2009). The continuous usage of plants that possess therapeutic properties as a remedy have been observed in developing countries, as they see no risk in using medicinal plants. Although these compounds are of important value, preliminary data reports that plants have a potential to disrupt processes of mitosis and also cause changes in the genetic material (Akintonwa et al., 2009). Toxicity of plant extracts can also be fatal due to poisoning expressed through vomiting, lightheadedness, and heart block (Khan et al., 2010) and consumption of high doses of plant extract can induce damage to the liver and kidney (Al-Nuaimi, 2018). Therefore, efforts on exploring the safe preparation and administration of medicinal plant extracts should be strengthened.

Tamarind is widely known as a souring condiment, where its pulp is largely consumed raw, sweetened or candied and have a rich source of alkaloids, reducing sugar, tannins, and glycosides, saponin, tannins, and flavonoids (Anu et al., 2014; Adedayo et al., 2016). In traditional medicine, almost all parts of the tamarind plant are used (Deepak et al., 2014) and contain medicinal properties (De Vera et al., 2016). Due to its minerals, high fiber and ascorbic acid content (Khanzada et al., 2008), it is being utilized as a laxative and in the prevention of scurvy, respectively (Kuru, 2014). For years, it has been known to be useful in treating constipation, sore throat, liver, gall and bile disorders. The crushed leaves and pulp of tamarind are reported to relieve pain and inflammation on joints (Aida et al., 2001; Asase et al., 2005; Vyas et al., 2009). Published literature also supports its antibacterial (Abubakar et al., 2008), hepatoprotective (Pimple et al., 2007), antivenom (Ushanandini et al., 2006), antidiabetic (Roy et al., 2010) and analgesic properties (Khalid et al., 2010). However, the presence of flavonoids, alkaloids and saponins may reinforce $T$. indica pulp extract's toxicity. In high concentrations, flavonoids are found to promote oxidation which may disrupt fetal development if consumed excessively (Hodek et al., 2002). Alkaloids are known to have caused developmental defects in humans and animals; some phytoconstituents can also induce multiple congenital contracture-type deformities (Green et al., 2018). As reported by Shu et al. (2015), saponins can damage the ovary and uterus leading to maternal toxicity, affecting the offspring after birth. Further, a report of De Vera et al. (2016), presented the lethal and teratogenic effect of basil and tamarind leaf extract in which mortality occurred in high concentrations of both extracts and deformities on the developing embryo were also observed.

It is generally assumed that medicinal plants are safe to use due to its numerous therapeutic properties. Despite the numerous advantages of tamarind's phytochemicals, findings on the toxicity of high doses of $T$. indica stem bark crude extract has been reported by Nwodo et al. (2011). However, research on the embryotoxic and teratogenic potential of the pulp extract of $T$. indica remains scanty. Thus, this study aimed to examine and report the embryotoxic and teratogenic influence of $T$. indica pulp extract on the development of zebrafish embryos and larvae through a comprehensive set of morphometric and morphological endpoints.

\section{Material and Methods}

\section{Tamarindus indica Linn. fruit pulp storage}

The ripe Tamarindus indica fruit pulp was collected a week prior to the test exposure, air dried $\left(25 \pm 0.1{ }^{\circ} \mathrm{C}\right)$ for $72 \mathrm{~h}$ and was stored in an aluminum foil until use. Species identification was validated by the Department of Agriculture - Region 7 Office, Maguikay, Mandaue City.

\section{Preparation of Tamarindus indica pulp extract}

Each $50 \mathrm{~g}$ of fruit pulp was mixed with $100 \mathrm{~mL}$ of warm $\mathrm{dH}_{2} \mathrm{O}\left(80^{\circ} \mathrm{C}\right)$ and was blended using a US Tradition blender for a minute; the mixture was homogenized using a rotary shaker at $200 \mathrm{rpm}$ for 10 minutes. Homogenate was sieved using cheesecloth and was filtered using Whatman No. 1 filter paper to acquire fine texture. Rotary evaporator set at $90^{\circ} \mathrm{C}$ was used in obtaining the crude extract. The crude extract was subjected to serial dilution (Adedayo et al., 2016; Adeniyi et al., 2017).

\section{Test organism}

The zebrafish breeding stock was maintained in accordance with OECD Fish Embryo Acute Toxicity Test (FET) and regulations of USC-IACUC (AUP No. 83/2018-12). A sample of the breeding stock was tested, and species identification was confirmed by the University of San Carlos - DAPV to be a wild-type Danio rerio. A breeding stock that consists of 12 female and 6 male wild-type zebrafish (aged 4 to 15 months) were obtained from a private fish breeder. 
Prior to experimentation, they were examined from macroscopically discernable symptoms of infection (Hallare et al., 2014) and were acclimated for two (2) weeks prior to spawning.

Adult fish was maintained in a $76 \mathrm{~L}$ aquarium tank with a minimum loading capacity of $1-\mathrm{L}$ per fish using aged and dechlorinated water as the system water. Culture conditions were set to $26 \pm 1{ }^{\circ} \mathrm{C}$ at a 10 -h light / 14-h night light regime (Halili and Quilang, 2011). Water parameters were monitored every other day and maintained to the recommended optimum range (Table 1). The system water of the aquarium was changed whenever the water quality parameters are higher than the optimum range for the zebrafish. The fish were fed three times a day with fish flakes and blood worms three days before spawning (Westerfield, 2000).

Table-1. Water quality parameters for the zebrafish aquarium (Avdesh et al., 2012).

\begin{tabular}{|l|l|}
\hline Parameter & Optimal Range \\
\hline Alkalinity & $50-150 \mathrm{mg} / \mathrm{L} \mathrm{CaCO}_{3}$ \\
\hline Ammonia & $<0.02 \mathrm{mg} / \mathrm{L}$ \\
\hline Nitrate $\left(\mathrm{NO}^{3-}\right)$ & $<50 \mathrm{mg} / \mathrm{L}$ \\
\hline Nitrite $\left(\mathrm{NO}^{2-}\right)$ & $<0.1 \mathrm{mg} / \mathrm{L}$ \\
\hline $\mathrm{pH}$ & $6.8-7.5(6.0-8.5$ tolerated $)$ \\
\hline Salinity & $0.5-1 \mathrm{~g} / \mathrm{L}$ \\
\hline Temperature & $26-28.5^{\circ} \mathrm{C}$ \\
\hline
\end{tabular}

\section{Spawning and collection of fertilized eggs}

Sexually matured adult zebrafish were transferred into five breeding tanks with a ratio of 2:1 per breeding tank. The breeding tank used a fabric mesh to prevent the parents from eating their eggs and green plastic plants were added as a spawning stimulant. Spawning and fertilization takes place within 30 minutes after the onset of light (Hallare et al., 2004). About 30 to 60 minutes after spawning, the eggs were collected using wide tip pipettes. The eggs were washed with system water and placed in a temperature-controlled petri dish and were viewed under a stereomicroscope to count and sort viable eggs. Fertilized eggs were then separated from the unfertilized eggs using a pipette.

\section{Euthanasia and proper disposal of zebrafish}

All exposed embryos were euthanized by submersion in iced water for at least 10 minutes (Matthews and Varga, 2012). Zebrafish carcasses were disposed of according to the Medical Pathological Waste Disposal Guidelines of the National Institutes of Health (NIH).

\section{Embryotoxicity and teratogenicity evaluation} Experimental design and exposure test

A series of range-finding tests was done to get the appropriate concentration of $T$. indica pulp extract. This study employed a Completely Randomized Design (CRD), ensuring that all test solutions ( $T$. indica pulp extract), negative control (system water) and positive control (1.5\% ethanol) will be tested on zebrafish embryos. There were three replicates in each treatment and control groups with three trials. A 60 $\mathrm{mm}$ petri dish was used wherein sixty embryos per treatment (three embryos per petri dish) was transferred individually to each dish. The three eggs in each dish represents the replicates. Each petri dish has $7 \mathrm{~mL}$ solutions of each of the treatment and control groups. A static non-renewal exposure was maintained throughout the duration of the test (Organization for Economic Cooperation and Development 236). For the post test, there were three replicates in all experimental and control groups ran in three consecutive trials. Ten embryos per treatment (one embryo per petri dish) was transferred individually to each Petri dish.

Table-2. Endpoints for the zebrafish developmental toxicity assay and classification according to teratogenicity and embryotoxicity (Van den Bulck et al., 2011).

\begin{tabular}{|l|c|c|c|}
\hline $\begin{array}{l}\text { Embryotoxic } \\
\text { Endpoints }\end{array}$ & Criteria & $\begin{array}{c}\text { Teratogenic } \\
\text { Endpoints }\end{array}$ & Criteria \\
\hline Coagulation & $\begin{array}{c}\text { Eggs become } \\
\text { coagulated }\end{array}$ & $\begin{array}{c}\text { Non-detachment of } \\
\text { tail }\end{array}$ & $\begin{array}{c}\text { Tails don't detach } \\
\text { from the body }\end{array}$ \\
\hline Heartbeat & $\begin{array}{c}\text { Lack of } \\
\text { heartbeat }\end{array}$ & $\begin{array}{c}\text { Non-formation of } \\
\text { somite }\end{array}$ & $\begin{array}{c}\text { No somite } \\
\text { formations }\end{array}$ \\
\hline Motility & No movement & Edema & Bloated yolk sac \\
\hline Hatch rate & $\begin{array}{c}\text { Hatched or } \\
\text { unhatched }\end{array}$ & $\begin{array}{c}\text { Spine and tail } \\
\text { malformation }\end{array}$ & $\begin{array}{c}\text { Short, curly or bent } \\
\text { spine or/and tail }\end{array}$ \\
\hline
\end{tabular}

After collection, the zebrafish embryos were exposed to the treatment of $T$. indica pulp extract as well as to the control groups. Three arbitrary time points of observation were considered: 24,48 and 72 hours post fertilization [hpf] (Hallare et al., 2014). Scores were assigned for each criterion in a binomial manner [i.e. ' 1 ' was assigned for abnormal and ' 0 ' was assigned for normal characteristics] (Hallare et al., 2014) (Table 2 and 3). Based on the score assigned for a particular characteristic, an overall score for percentage effect was calculated for each treatment in the experiment. An embryo is perceived to be either normal (all score $=0)$, malformed, or dead embryos (score $=1)$ (Table 2 and 3). Thus, cumulative percentage for each time point of the observed individuals that were dead or malformed was taken. 
Table-3. An overview of the scoring criteria of the developmental endpoints evaluated for the embryotoxic and teratogenic potential of TIPE.

\begin{tabular}{|c|c|c|c|}
\hline \multirow{4}{*}{$\begin{array}{c}\text { Embryotoxic } \\
\text { Endpoints }\end{array}$} & \multicolumn{3}{|c|}{ Developmental Endpoints Criteria } \\
\cline { 2 - 4 } & Coagulation & $\begin{array}{c}\text { Egg develops } \\
\text { normally }\end{array}$ & $\begin{array}{c}\text { Egg coagulates; forms } \\
\text { solid white particle }\end{array}$ \\
\cline { 2 - 4 } & Heartbeat & $\begin{array}{c}\text { Presence of } \\
\text { heartbeat }\end{array}$ & Lack of heartbeat \\
\cline { 2 - 5 } & Motility & $\begin{array}{c}\text { Movement } \\
\text { through stimulus }\end{array}$ & No movement \\
\cline { 2 - 5 } Tatch rate & Egg is hatched & Egg is unhatched \\
\hline \multirow{4}{*}{$\begin{array}{c}\text { Teratogenic } \\
\text { Endpoints }\end{array}$} & $\begin{array}{c}\text { Tail } \\
\text { detachment }\end{array}$ & $\begin{array}{c}\text { Tail is detached } \\
\text { from the body }\end{array}$ & $\begin{array}{c}\text { Tails don't detach } \\
\text { from the body }\end{array}$ \\
\cline { 2 - 5 } & $\begin{array}{c}\text { Somite } \\
\text { formation }\end{array}$ & $\begin{array}{c}\text { There is formation } \\
\text { of somites }\end{array}$ & $\begin{array}{c}\text { No formation of } \\
\text { somites }\end{array}$ \\
\cline { 2 - 4 } & $\begin{array}{c}\text { Edema } \\
\text { Spine } \\
\text { malformation }\end{array}$ & Normal yolk sac & Bloated yolk sac \\
\cline { 2 - 4 } & $\begin{array}{c}\text { Tail } \\
\text { malformation }\end{array}$ & Normal tail & $\begin{array}{c}\text { Short, curved or bent } \\
\text { tail }\end{array}$ \\
\hline
\end{tabular}

\section{Morphological parameters}

The concentrations were classified as teratogenic and/or embryotoxic by the given endpoints. The embryotoxic endpoints are: (a) coagulation, (b) heartbeat, (c) hatch rate and (d) motility. While the teratogenic endpoints are: (e) non-somite formation, (f) non-detachment of tail, (g) yolk sac edema, (h) spine deformation and (i) tail deformation (Van den Bulck et al., 2011), (Consuegra et al., 2020).

According to the proposed hypothesis of Van den Bulck et al. (2011), a teratogenic compound would alter the formation of an organ or tissue, i.e. perturbed a developmental pathway and could be identified by screening a series of endpoints relating to developmental malformations, e.g. abnormal jaw, heart or body morphology. Thus, the chosen endpoints for teratogenicity were; non-somite formation, nondetachment of tail, yolk sac edema, spine and tail malformation. In yolk sac edema, the yolk sac abnormally becomes bloated with added fluids. Spine and tail malformation criteria show an increasing severity in body shape (i.e., short body, curly or bent tail or spine) (Brannen et al., 2010). For the criteria on larvae motility, touch response of the zebrafish was noted if it recoils after touch or no movement at all.

In contrast with teratogenicity, a compound that caused embryotoxicity would cause overall toxicity leading to cell death and ultimate lethality or could affect organs and tissues after their development as tissue degradation or organ dysfunction (Van den Bulck et al., 2011). Hence, making the OECD 236 criteria a suitable endpoint for embryotoxicity. The OECD 236 criteria were namely: coagulation of embryos, no movement, lack of heartbeat and hatch rate. The number of hatched and living embryos was also recorded. For every observation done under the stereoscope, photographic documentation was done for every embryo. Each scale calibrated image of the test organism was analyzed for the measurement of the total body length (snout to the base of the tail) (Singleman and Holtzman, 2014) and tail angle using ImageJ software. All the eight endpoints were observed across the 72-hour duration of the experimentation in each of the treatments.

\section{Teratogenicity index (TI)}

Teratogenicity was evaluated by comparing the treatments that cause lethality and concentrations that cause developmental effects (Haldi et al., 2011). $\mathrm{EC}_{50}$ ideally includes a low concentration that exhibits few or no malformations, a high concentration that exhibits several malformations (but not death), and two concentrations in the middle of the range; a concentration-response curve can then be generated (Haldi et al., 2011).

where:

$\mathrm{TI}=$ Teratogenic index

LC50 $=$ Lethal Concentration at 50\%

EC50 $=$ Median Effective Concentration

If:

TI $>1$ - teratogenic

TI $<1$ - nonteratogenic

$\mathrm{TI}=1-$ toxicity assessment will be performed at the exact LC50 concentration to determine if the zebrafish exhibits malformations at that concentration

To get $\mathrm{LC}_{50}$, a linear equation was defined to find the values of $\mathrm{m}$ and $\mathrm{c}$, with the linear equation format (2).

where:

$\mathrm{y}=$ number of deaths $\quad \mathrm{x}=$ concentration of $T$. indica pulp extract

$\mathrm{a}=$ gradient $\quad \mathrm{b}=$ constant

While $\mathrm{EC}_{50}$ is defined as:

where:

$\log x 0=$ concentration of the half response; $x=$ concentration of $T$. indica pulp extract 


\section{Statistical analysis}

Linear regression analysis was used to observe the relationship between the lethality and dose concentration of $T$. indica pulp extract on zebrafish, and to evaluate the relationship between the independent variable and dependent variable as well as generate a regression equation (Schneider et al., 2010). In computing the $\mathrm{LC}_{50}$, a probit regression analysis was used wherein the percent mortality was transformed into probits or probability units based on Finney's table (1952). Probit was graphed against $\log _{10}$ concentrations thus yielding a slope-intercept equation. From this equation $(\mathrm{y}=\mathrm{ax}+\mathrm{b})$, the slope $(\mathrm{x})$ was then calculated (Hallare et al., 2014). Subsequently, $\mathrm{LC}_{50}$ was inferred as the antilog of $\mathrm{x}$ with $95 \%$ confidence for the three-time points. Significant results from Analysis of Variance (ANOVA) were further analyzed using Tukey-post hoc test to determine which among the groups mean differ.

\section{Results}

Effect of $T$. indica pulp extract on the total body length (TBL) and trunk-tail angle (TTA)

To obtain a quantitative and unbiased method of morphological assessment, images of the orientation of the fish larvae at $72 \mathrm{hpf}$ were taken and morphometric parameters were measured as a manifestation of the influence of $T$. indica pulp extract concentrations on the growth of the larvae. In each group (experimental or control), every surviving larva was measured for its TBL and TTA (Table 4). Based on the statistical treatment of data (one-way ANOVA), results of the TBL and TTA revealed that the larvae from all the groups were statistically significant $(\mathrm{p} \leq 0.00)$ (Table 4). This means that the null hypothesis is rejected (i.e. there is no significant difference in the TBL and TTA of zebrafish larvae after exposure to $T$. indica pulp extract). This result implies that the zebrafish larvae exposed to the treatment ( $T$. indica pulp extract concentrations in $\mathrm{mg} / \mathrm{L}$ ) and control groups (ethanol and system water) significantly differ from each other in terms of its means \pm standard deviation (SD) of the TBL and TTA (Fig. 1 and Table 4). Also, results from the Post-hoc test showed that the TBL and TTA across groups were statistically significant $(\mathrm{p} \leq 0.05)$, to some groups only which suggests that each treatment is not comparable to some in terms of the influence of $T$. indica pulp extract on TBL and TTA of the zebrafish larvae.
Table-4. Average Total Body Length and Trunk-tail Angle of zebrafish embryos subjected to various control and TIPE treatments observed at $72 \mathrm{hpf}$.

\begin{tabular}{|c|c|c|}
\hline \multirow{2}{*}{ Groups } & $\begin{array}{c}\text { Total Body Length } \\
(\mathbf{m m})\end{array}$ & $\begin{array}{c}\text { Trunk Tail Angle } \\
(\mathbf{d e g r e e})\end{array}$ \\
\cline { 2 - 3 } & Mean $\pm S D$ & Mean $\pm S D$ \\
\hline $\begin{array}{c}\text { Negative Control } \\
\text { (System Water) }\end{array}$ & $2.97 \pm 0.39^{\mathrm{a}}$ & $180 \pm 0.00^{\mathrm{a}}$ \\
\hline $\begin{array}{c}\text { Positive Control } \\
(1.5 \% \text { Ethanol) }\end{array}$ & $2.69 \pm 0.37^{\mathrm{a}, \mathrm{b}}$ & $81.67 \pm 11.10^{\mathrm{b}}$ \\
\hline A - 2500 ppm & $0.20 \pm 0.42^{\mathrm{d}}$ & $12.00 \pm 25.30^{\mathrm{c}}$ \\
\hline B - 1250 ppm & $0.86 \pm 0.33^{\mathrm{c}}$ & $49.69 \pm 18.92^{\mathrm{d}}$ \\
\hline C - 625 ppm & $2.45 \pm 0.27^{\mathrm{b}}$ & $139.06 \pm 15.39^{\mathrm{e}}$ \\
\hline D - 312.5 ppm & $2.55 \pm 0.28^{\mathrm{a}, \mathrm{b}}$ & $144.00 \pm 15.78^{\mathrm{e}}$ \\
\hline ANOVA $(\mathrm{p} \leq 0.05)$ & $\mathrm{sig}$ & $\mathrm{sig}$ \\
\hline
\end{tabular}

There is an increasing trend in the TBL and TTA of the zebrafish larvae as the $T$. indica pulp extract concentration decreases. Treatment A $(2,500 \mathrm{mg} / \mathrm{L})$ recorded the lowest means \pm SD (with error bars) in both total body length and trunk-tail angle with values $0.2000 \pm 0.4200$ and $12.00 \pm 25.30$, respectively (Fig 1 and Table 4). As the concentration increases, decreasing values of TBL and TTA indicate the inversely proportional relationship of $T$. indica pulp extract concentration to morphometric growth parameters.

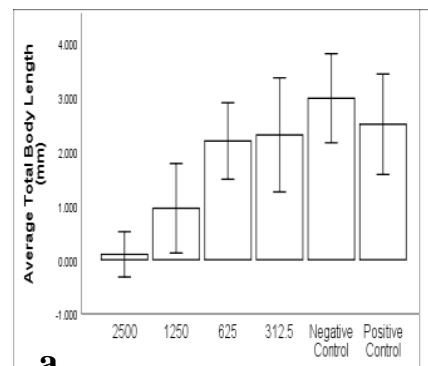

a. Concentration (ppm)

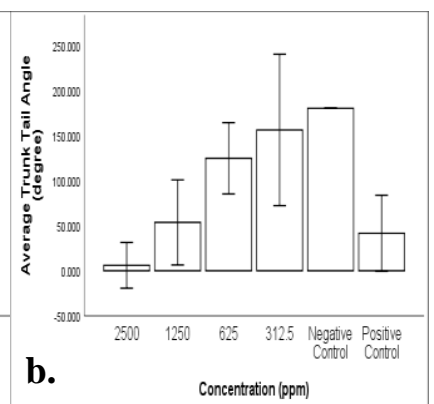

Figure-1. The effects of different concentrations of TIPE on the development of the zebrafish embryos in terms of total body length and trunk tail angle.

(a.) Mean body lengths ( $\mathrm{mm})$ and (b.) trunk-tail angle $\left({ }^{\circ}\right)$ of the embryos examined at $72 \mathrm{hpf}$. The values are expressed as mean $\pm \mathrm{SD}$ of $n=10$ embryos.

When exposed to high concentrations of $T$. indica pulp extract, the interference on growth development especially in trunk-tail angle, suggests that $T$. indica pulp extract may have induced malformations in the larvae during its period of exposure (Fig 1). Results from the assessment may provide insights on the influence of $T$. indica pulp extract on growth parameters, as TBL and TTA are also useful parameters of measuring teratogenicity (Lantz- McPeak et al., 2015). 


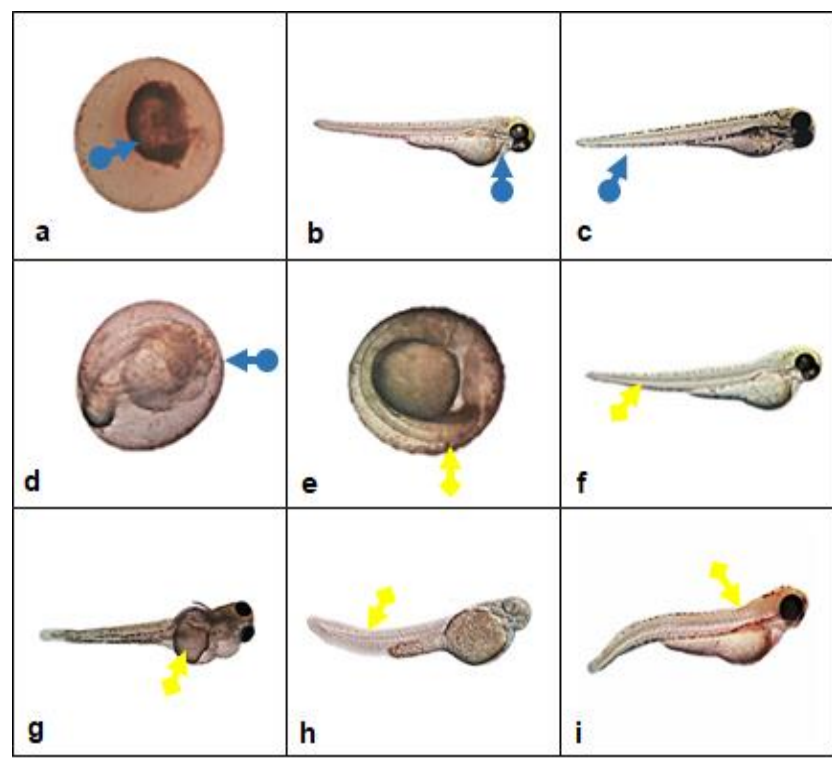

Figure-2 (a-i). Morphological deformities observed in the embryos exposed to TIPE concentrations (a) coagulation; (b) absence of heartbeat, (c) absence of motility, (d) hatch abnormality, (e) non-detached tail, (f) non-somite formation, (g) edema malformation, (h) tail malformation and (i) spine malformation. Yellow arrow $=$ teratogenic ; Blue arrow $=$ embryotoxic .

\section{Evaluation on the developmental endpoints}

The criteria for the different morphological endpoints were scored through a binomial method and the scoring was subjective to the viewpoint of the solitary observer that ought to fit the criterion (Table 6). The parameters observed for the embryotoxic potential of $T$. indica pulp extract were lack of heartbeat, motility, hatch rate and coagulation. In a wide range of $T$. indica pulp extract concentrations, starting from $312.5 \mathrm{mg} / \mathrm{L}$ to $2,500 \mathrm{mg} / \mathrm{L}$, coagulation of embryos was the most recorded parameter to elicit toxicity. Furthermore, embryos exposed to earlier test concentrations of $2,500 \mathrm{mg} / \mathrm{L}$ to $10,000 \mathrm{mg} / \mathrm{L}$ have accounted to $100 \%$ mortality at $24 \mathrm{hpf}$. Hence, the potency of the embryotoxic property of $T$. indica pulp extract could be observed at higher concentrations that are above 2,500 $\mathrm{mg} / \mathrm{L}$ and could take effect at the earliest time point through coagulation. Coagulated embryos appeared as a solid opaque granule inside the chorion and the non-coagulated embryos remained intact inside the chorion or were likely to hatch (Fig. 2).

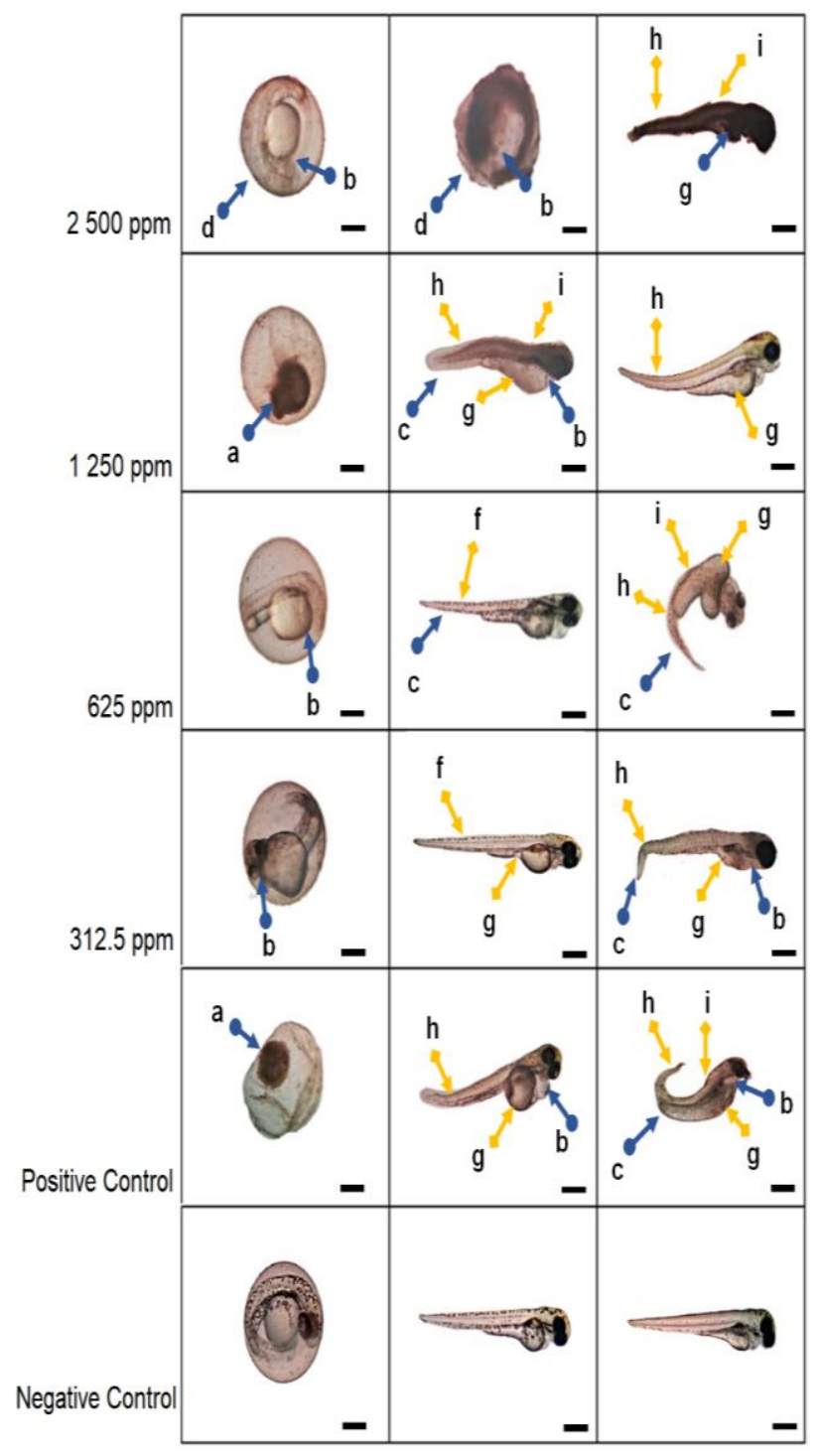

Figure-3. Morphological characteristics evaluated at different time points to assess the 3 embryotoxic and teratogenic potential of TIPE. Arrows indicate the embryotoxic or 4 teratogenic effects manifested at different TIPE concentrations: (a) coagulation, (b) absence of heart beat, (c) absence of motility, (d) hatch abnormality, (e) non-detached tai, (f) nonsomite formation, (g) edema malformation, (h) tail malformation and (i) spine malformation. All Scale bars are at $1 \mathrm{~mm}$. 
Table-5. Summary of the average mortality of Danio rerio embryos and larvae after $72 \mathrm{hr}$ of exposure to different TIPE concentrations. *Values were derived from the results of the different exposure test.

\begin{tabular}{|c|c|c|c|c|c|c|c|}
\hline $\begin{array}{l}\text { Plant } \\
\text { Extract }\end{array}$ & $\begin{array}{c}\text { Exposure } \\
\text { test }\end{array}$ & \begin{tabular}{|c|} 
Concentration \\
$(\mathbf{p p m})$
\end{tabular} & Treatment & $\begin{array}{c}\text { Total no. of } \\
\text { surviving embryos }\end{array}$ & $\begin{array}{c}\text { Total no. of } \\
\text { dead embryos }\end{array}$ & $\begin{array}{l}\text { Total no. of } \\
\text { samples }\end{array}$ & $\begin{array}{c}\text { Percent } \\
\text { Mortality }\end{array}$ \\
\hline \multirow{13}{*}{ TIPE } & \multirow{5}{*}{ 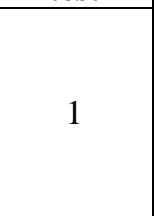 } & 10000 & A & 0 & 60 & 60 & $100 \%$ \\
\hline & & 1000 & $\mathrm{~B}$ & 47 & 13 & 60 & $22 \%$ \\
\hline & & 100 & $\mathrm{C}$ & 47 & 13 & 60 & $22 \%$ \\
\hline & & 10 & $\mathrm{D}$ & 51 & 9 & 60 & $15 \%$ \\
\hline & & 1 & E & 47 & 13 & 60 & $22 \%$ \\
\hline & \multirow{4}{*}{2} & 10000 & A & 0 & 30 & 30 & $100 \%$ \\
\hline & & 7500 & B & 0 & 30 & 30 & $100 \%$ \\
\hline & & 5000 & $\mathrm{C}$ & 0 & 30 & 30 & $100 \%$ \\
\hline & & 2500 & $\mathrm{D}$ & 0 & 30 & 30 & $100 \%$ \\
\hline & \multirow{4}{*}{3} & 2000 & $\mathrm{~A}$ & 9 & 21 & 30 & $97 \%$ \\
\hline & & 1750 & $\mathrm{~B}$ & 6 & 24 & 30 & $67 \%$ \\
\hline & & 1500 & $\mathrm{C}$ & 8 & 22 & 30 & $23 \%$ \\
\hline & & 1250 & $\mathrm{D}$ & 17 & 13 & 30 & $23 \%$ \\
\hline
\end{tabular}

Table-6. Summary of the morphological characteristics evaluated as measures of the embryotoxic and teratogenic potential of the TIPE extract at each timepoint of observation $(24,48$ and $72 \mathrm{hpf})$.

\begin{tabular}{|c|c|c|c|c|}
\hline & \multirow{2}{*}{$\begin{array}{c}\text { Developmental } \\
\text { endpoints evaluated }\end{array}$} & \multicolumn{3}{|c|}{$\begin{array}{c}\text { Time point for observation } \\
\text { of normal development }\end{array}$} \\
\hline & & \multicolumn{3}{|c|}{$($ normal $=0 ;$ abnormal $=1)$} \\
\hline \multirow{6}{*}{ Embryotoxicity } & & $24 \mathrm{hpf}$ & $48 \mathrm{hpf}$ & 72hpf \\
\hline & Coagulation & $\checkmark$ & $\checkmark$ & $\checkmark$ \\
\hline & Heartbeat & $x$ & $\sqrt{ }$ & $\sqrt{ }$ \\
\hline & Motility & $x$ & $\checkmark$ & $\checkmark$ \\
\hline & Hatch rate & $x$ & $\checkmark$ & $\sqrt{ }$ \\
\hline & & $24 \mathrm{hpf}$ & $48 \mathrm{hpf}$ & $72 \mathrm{hpf}$ \\
\hline \multirow{5}{*}{ Teratogenicity } & Non-detachment of tail & $\checkmark$ & $\checkmark$ & $\checkmark$ \\
\hline & $\begin{array}{c}\text { Non-formation of } \\
\text { somite }\end{array}$ & $\checkmark$ & $\checkmark$ & $\checkmark$ \\
\hline & Edema & $x$ & $x$ & $\sqrt{ }$ \\
\hline & Tail deformation & $x$ & $x$ & $\checkmark$ \\
\hline & Spine deformation & $x$ & $x$ & $\sqrt{ }$ \\
\hline
\end{tabular}

Non-coagulated, hatched embryos then tend to die or survive at $48 \mathrm{hpf}$ or $72 \mathrm{hpf}$. After these time points, the surviving embryos are observed to develop malformations. However, non-formation of somites was already observed at $24 \mathrm{hpf}$ in different $T$. indica pulp extract concentrations (Fig. 3). As such, this may propose that exposure of embryos to $T$. indica pulp extract may have triggered a disturbance during the development of the segmental precursors of somite formation that lead to the malformations of the exposed surviving embryos at $72 \mathrm{hpf}$. At $72 \mathrm{hpf}$, the malformations observed in the surviving embryos also included yolk edema, tail and spine malformation exposed in $625 \mathrm{mg} / \mathrm{L}$ (Fig. 3). Out of all parameters for teratogenicity, non-detachment of tail was the least expressed among the surviving embryos.
Evaluation on the $T$. indica pulp extract embryotoxic and teratogenic potential

The embryotoxic effect of all $T$. indica pulp extract concentrations to exposed zebrafish embryos was observed to behave in a concentration dependent manner. The cumulative percent mortality for Treatment A $(2,500 \mathrm{mg} / \mathrm{L})$ was $97 \%$; Treatment B $(1,250 \mathrm{mg} / \mathrm{L})$ was $67 \%$; Treatment C $(625 \mathrm{mg} / \mathrm{L})$ was $23 \%$; lastly, Treatment D (312.5 mg/L) was $23 \%$ (Table 7). Clearly, the incidence of mortality decreases as the degree of concentration decreases and vice versa. The teratogenicity of $T$. indica pulp extract, by contrast, manifested in lower concentrations. Higher incidence of malformation occurs in Treatment $\mathrm{D}$ with $87 \%$, Treatment C with $90 \%$, Treatment B with $73 \%$ and Treatment A with $43 \%$. As such, the incidence of malformations decreases as the $T$. indica pulp extract concentration increases.

Evaluation on the $\mathrm{LC}_{50}, \mathrm{EC}_{50}$ and TI values of $\boldsymbol{T}$. indica pulp extract

The embryotoxic and teratogenic potential of $T$. indica pulp extract was evaluated and determined from three independent trials of $T$. indica pulp extract exposure to the test organisms. From the results, the trend revealed that the proportionality of the embryotoxic and teratogenic potential of the pulp extract behaves inversely, as reflected in the values of $\mathrm{EC}_{50}$ and $\mathrm{LC}_{50}$ (Fig.4). The estimated LC50 values of the succeeding timepoints were $3.163 \mathrm{mg} / \mathrm{L}, 3.010 \mathrm{mg} / \mathrm{L}$, and 2.904 $\mathrm{mg} / \mathrm{L}$, respectively (Table 8 ). For $\mathrm{EC}_{50}$, the analysis revealed the values $0.848 \mathrm{mg} / \mathrm{L}, 9.813 \mathrm{mg} / \mathrm{L}$ and 2.572 $\mathrm{mg} / \mathrm{L}$ for the three timepoints respectively. These values were expressed as $\log 10$. 
Table-7. Number of dead zebrafish (Danio rerio) embryo after the exposure of TIPE in different concentrations at different time endpoints and percent mortality with the median lethal concentration (LC50) value.

\begin{tabular}{|c|c|c|c|c|c|c|c|c|c|c|c|c|c|c|}
\hline \multicolumn{15}{|c|}{ Experimental Group } \\
\hline \multirow{2}{*}{$\begin{array}{c}\text { Plant } \\
\text { Extract }\end{array}$} & \multirow{2}{*}{$\begin{array}{c}\text { Time } \\
\text { endpoints }\end{array}$} & \multicolumn{2}{|c|}{ Concentration } & \multicolumn{3}{|c|}{$\begin{array}{c}\text { Average no. of dead } \\
\text { embryo }\end{array}$} & \multirow{2}{*}{$\begin{array}{c}\text { Total no. } \\
\text { of dead } \\
\text { embryos } \\
\text { (3 Trials) }\end{array}$} & \multirow{2}{*}{$\begin{array}{c}\text { Total of } \\
\text { surviving } \\
\text { embryos }\end{array}$} & \multirow{2}{*}{$\begin{array}{l}\text { Sample } \\
\text { Size }\end{array}$} & \multirow{2}{*}{$\begin{array}{c}\% \\
\text { Mortality }\end{array}$} & \multicolumn{2}{|c|}{$\mathrm{LC}_{50}$} & \multicolumn{2}{|c|}{$\mathrm{EC}_{50}$} \\
\hline & & ppm & Treatment & $\begin{array}{c}\mathrm{T} 1 \\
(\mathrm{n}=30)\end{array}$ & $\begin{array}{c}\mathrm{T} 2 \\
(\mathrm{n}=30)\end{array}$ & $\begin{array}{c}\mathrm{T} 3 \\
(\mathrm{n}=30)\end{array}$ & & & & & $\log 10$ & ppm & $\log 10$ & ppm \\
\hline \multirow{12}{*}{$\begin{array}{l}\text { Tamarindus } \\
\text { indica Linn. } \\
\text { Pulp Extract } \\
\text { (TIPE) }\end{array}$} & \multirow{4}{*}{$24 \mathrm{hpf}$} & 2500 & A & 24 & 14 & 30 & 23 & 7 & 30 & 77 & \multirow{4}{*}{3.163} & \multirow{4}{*}{1455} & \multirow{4}{*}{0.848} & \multirow{4}{*}{7} \\
\hline & & 1250 & $\mathrm{~B}$ & 21 & 5 & 14 & 13 & 17 & 30 & 43 & & & & \\
\hline & & 625 & $\mathrm{C}$ & 7 & 1 & 2 & 3 & 27 & 30 & 10 & & & & \\
\hline & & 312.5 & $\mathrm{D}$ & 3 & 1 & 0 & 1 & 26 & 30 & 13 & & & & \\
\hline & \multirow{4}{*}{$48 \mathrm{hpf}$} & 2500 & A & 29 & 20 & 30 & 26 & 4 & 30 & 87 & \multirow{4}{*}{3.01} & \multirow{4}{*}{1023} & \multirow{4}{*}{9.813} & \multirow{4}{*}{$\begin{array}{c}7 \mathrm{E}+ \\
09\end{array}$} \\
\hline & & 1250 & $\mathrm{~B}$ & 25 & 8 & 21 & 18 & 12 & 30 & 60 & & & & \\
\hline & & 625 & $\mathrm{C}$ & 7 & 8 & 2 & 6 & 24 & 30 & 20 & & & & \\
\hline & & 312.5 & $\mathrm{D}$ & 3 & 10 & 0 & 4 & 26 & 30 & 13 & & & & \\
\hline & \multirow{4}{*}{$72 \mathrm{hpf}$} & 2500 & A & 30 & 28 & 30 & 29 & 1 & 30 & 97 & \multirow{4}{*}{2.904} & \multirow{4}{*}{801} & \multirow{4}{*}{2.572} & \multirow{4}{*}{374} \\
\hline & & 1250 & B & 26 & 12 & 21 & 20 & 10 & 30 & 67 & & & & \\
\hline & & 625 & $\mathrm{C}$ & 7 & 11 & 2 & 7 & 23 & 30 & 23 & & & & \\
\hline & & 312.5 & $\mathrm{D}$ & 8 & 14 & 0 & 7 & 23 & 30 & 23 & & & & \\
\hline
\end{tabular}
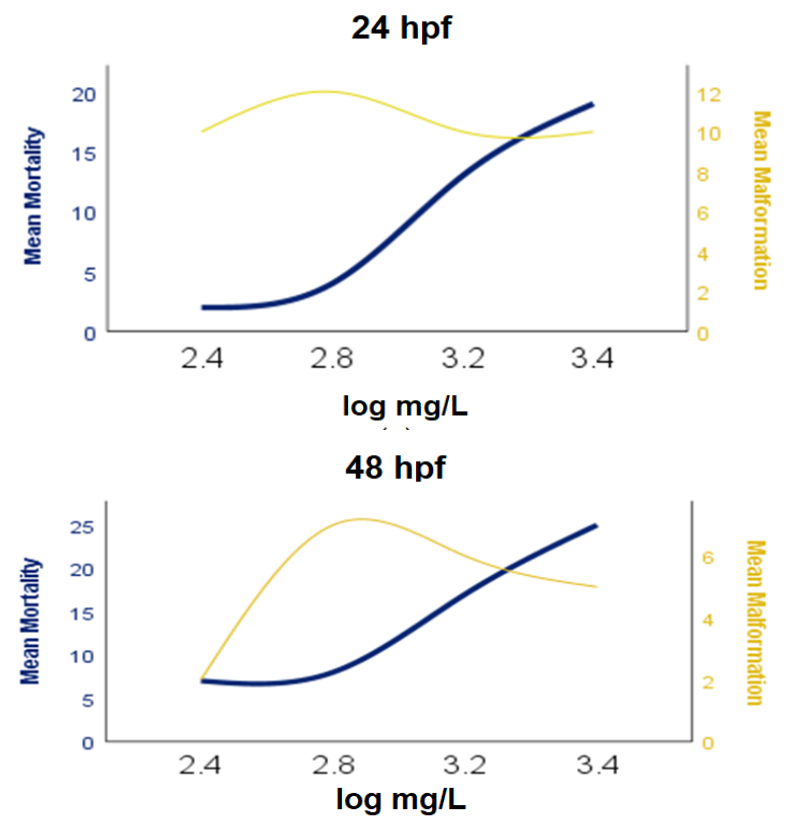

(b)

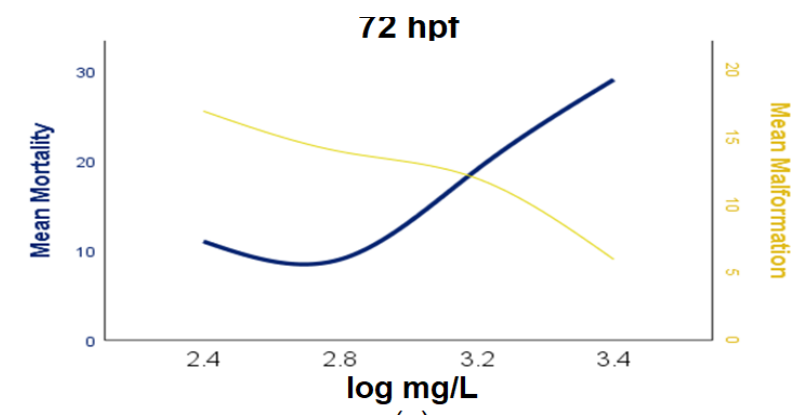

(c)

Figure-4 (a-c). Concentration-response curves for mortality and malformation of zebrafish embryos and larvae after exposure to different TIPE concentrations at different time points $(24,48$ and $72 \mathrm{hpf})$.
As to the teratogenicity of $T$. indica pulp extract, the calculated values of $\mathrm{EC}_{50}$ after $24 \mathrm{~h}$ is $7 \mathrm{mg} / \mathrm{L}$, after 48 and $72 \mathrm{~h}$ were 6504404445 and $374 \mathrm{mg} / \mathrm{L}$, respectively. At $48 \mathrm{hpf}$, the $\mathrm{EC}_{50}$ of the pulp extract was significantly higher than the other values of other timepoints. There was a dramatic increase of the $\mathrm{EC}_{50}$ value from $7 \mathrm{mg} / \mathrm{L}$ to $6504404445 \mathrm{mg} / \mathrm{L}$; also, a significant drop of values from 6504404445 $\mathrm{mg} / \mathrm{L}$ to $374 \mathrm{mg} / \mathrm{L}$ after the longest period of exposure (Table 7). T. indica pulp extract exhibited teratogenicity (TI>1) at $24 \mathrm{hpf}$ and $72 \mathrm{hpf}$ with a score of 3.73 and 1.13, respectively (Table 8). Occurrence of malformations in the exposed individuals was generally observed at the beginning or after a prolonged exposure to $T$. indica pulp extract (Table 8 and Fig. 4).

Table-8. $\mathrm{LC}_{50}, \mathrm{EC}_{50}$ and $\mathrm{TI}$ values derived from the concentration-response curves of TIPE concentrations based on its mean mortality and teratogenic effects at each time point. Values for $\mathrm{LC}_{50}, \mathrm{EC}_{50}$ and TI were represented by $\log 10$ PPM. *c.f. signify value cannot be found.

\begin{tabular}{|c|c|c|c|}
\hline Time point & $\begin{array}{c}\text { LC50 } \\
(\log 10 \text { PPM })\end{array}$ & $\begin{array}{c}\text { EC50 } \\
(\log 10 \text { PPM })\end{array}$ & $\begin{array}{c}\text { TI } \\
(\text { LC50/EC } 50)\end{array}$ \\
\hline $24 \mathrm{hpf}$ & 3.163 & 0.848 & 3.73 \\
\hline $48 \mathrm{hpf}$ & 3.010 & 9.813 & 0.31 \\
\hline $72 \mathrm{hpf}$ & 2.904 & 2.572 & 1.13 \\
\hline
\end{tabular}

\section{Discussion}

Researches on various substances that could inhibit embryotoxicity and teratogenicity in zebrafish embryos have increased in number throughout the 
years and results revealed promising breakthroughs (Ali et al., 2011). These researches operate on the assumptions that several factors could hinder a successful embryonic development - structural, functional or morphological abnormalities in the embryo (Gilbert-Barness, 2010; Costa et al., 2012). Hence, these researches were able to evaluate the toxicity of a substance by associating the effects of said substance at a certain development to the levels of exposure (Fraysse et al., 2006).

\section{Phytochemical screening}

The presence of alkaloids, flavonoids, saponins, and tannins from the qualitative screening of $T$. indica pulp extract corresponds to the results of other studies except for the presence of tannins (Abubakar et al., 2008; Nwodo et al., 2011; Adeniyi et al., 2017). Out of all the phytochemicals detected in $T$. indica pulp extract, the presence of flavonoids, alkaloids and saponins is of high relevance to the embryotoxic or teratogenic potential of the extract. Flavonoids have its drawback, yet it is a phytoconstituent considered as a strong antioxidant that increases a plant's antimicrobial activity (Havsteen, 2002). In high concentrations, flavonoids are found to promote oxidation which may disrupt fetal development if consumed excessively during pregnancy (Hodek et al., 2002). In addition, alkaloids are known to have caused developmental defects in humans and animals; some types of the phytoconstituent can also induce multiple congenital contracture-type deformities if consumed excessively (Green et al., 2018). Conversely, saponins are glycosides with foaming characteristics caused by the combination of a water-soluble sugar part and a fat-soluble sapogenin. One of the phytoconstituents detected in the extract, are known to protect the plant against microbes and exhibit an essential use in medicine (Caspi et al., 2017). However, saponins may cause several adverse effects including reproductive toxicity. As reported by Shu et al. (2015), saponins elicited maternal toxicity through damaging the ovary and uterus of the test organism and manifested to its offspring after birth. Hence, the presence of some phytochemicals that possess maternal or developmental toxicity support the proposition that $T$. indica pulp extract may possess embryotoxic and teratogenic potential.
Effect of $T$. indica pulp extract on the total body length (TBL) and trunk-tail angle (TTA)

For the TBL and TTA, concentration A has the highest standard deviation with values of 0.4200 and 23.30, respectively. This indicates that the measurements of the TBL and TTA of each zebrafish embryo vary extensively from the mean of concentration A $(2,500 \mathrm{mg} / \mathrm{L})$. The standard deviation values of TBL and TTA in $2,500 \mathrm{mg} / \mathrm{L}$ are relatively high, possibly because the length and trunk tail angle does not conform to normality (Sorrentino, 2010). Similarly, studies of Li et al. (2018) and Xia et al. (2017) presented a high standard deviation value on the highest concentration. On the other hand, low standard deviation in TBL was observed in Treatment $\mathrm{C}(625 \mathrm{mg} / \mathrm{L})$; indicating that the standard deviation in Treatment $\mathrm{C}$ are closely similar from the mean ranging from 2.180 to $2.720 \mathrm{~mm}$. However, the values of the TTA in the negative control showed the lowest standard deviation (0.00) since all data values are the same from the mean. This low standard deviation in negative control is fairly consistent to the study of Ong et al. (2017) wherein the standard deviation of the controls is closest to the mean.

\section{Evaluation on the developmental endpoints}

Coagulation of the embryos was the most recorded parameter of embryotoxicity, and most malformations were observed at embryos exposed to $T$. indica pulp extract after $48 \mathrm{hpf}$ or $72 \mathrm{hpf}$, similar to the findings of De Vera et al. (2016). The most noted parameter for malformation was the non-formation of somite observed at different concentrations. Somites are segmentation seen in the notochord which give rise to the axial skeleton and the skeletal muscle of the trunk of the zebrafish. Thus, abnormal growth of somite may lead to deformations of the body which can also inhibit the growth of embryos (Dubińska-Magiera et al., 2016). Throughout the process of tail elongation, movement of the pluripotent cells within the tailbud are critically accompanied with complex inductive mechanisms (Kanki and Ho, 1997). Conversely, a report from Mullins et al. (1996) suggests that the bending and shortening of the tail are regulated by genes influenced from the exposure to teratogenic substances. Hence, it can be inferred that manifestation of a non-detached tail in a developing embryo depends on the ability of the toxicant or substance to induce effects on the sensitive pluripotent cells in the tailbud. 
The development of the embryos was affected by the different $T$. indica pulp extract concentrations. It could possibly be due to the ability of the pulp extract to penetrate through the embryos' chorion pores enough to inhibit its tail and somite formation during its $24 \mathrm{hpf}$ development. This is in congruence to the results of Hallare et al. (2014) and Heger et al. (2012) in which mortality counts were all accounted for after $24 \mathrm{hr}$ of toxicant exposure. The toxicity observed in all the embryos may be a result of its exposure during the early stages of its embryonic development and its innate sensitivity to toxicants. Coagulation and other morphological malformations could also be influenced by the nature of the $T$. indica pulp extract concentrations; acidic with a $\mathrm{pH}$ range of 3.28 to 5.33 and presumably affect the development of embryos as these values are beyond the tolerated range for zebrafish development (Avdesh et al., 2012). Using the assigned endpoints, a certain treatment or compound can be easily classified as teratogenic and/or embryotoxic. A treatment or compound is considered embryotoxic if it results in cell death to the exposed organism. Developmental endpoints that fall for this parameter should display tissue degradation or dysfunctionality of organs that leads to overall toxicity (Van den Bulck et al., 2011) while teratogenic compounds can induce malformation that are expressed morphologically in an exposed organism such as spine or tail deformation. It alters the formation of an organ or tissue resulting in a perturbed development that could be identified by screening a series of endpoints relating to developmental malformations (Truong et al., 2011).

\section{Evaluation on the $T$. indica pulp extract embryotoxic and teratogenic potential}

The relationship of the embryotoxic and teratogenic potential of $T$. indica pulp extract appear to be inversely proportional with respect to the corresponding concentrations and time points. This presumption on the inverse relationship of the embryotoxic and teratogenic potential of $T$. indica pulp extract could be observed in the cumulative incidence of mortality and malformation of the different treatments. When incidence of mortality is high, occurrence of malformation is low and vice versa. Notably, occurrence of malformations in the developing larvae was more prominent at $625 \mathrm{mg} / \mathrm{L}$. Thus, it can be inferred that the embryotoxic and teratogenic potential of $T$. indica pulp extract behaves in a concentration-dependent manner and reveals the inverse proportionality between these two properties of the pulp extract.

Furthermore, the result of this study is in congruence with the results from the study of Rajagopal et al. (2017) and Alafiatayo et al. (2019). Both studies reported that toxicity of the turmeric extract manifested in higher levels of concentration on developing zebrafish embryos. Hence, it is suggested that developing zebrafish embryos are highly vulnerable during its early stages of development which explains the efficacy of plant extracts to induce toxicity.

\section{Evaluation on the $\mathrm{LC}_{50}, \mathrm{EC}_{50}$ and TI values of $T$. indica pulp extract}

For every time point, the values of $\mathrm{LC}_{50}$ and $\mathrm{EC}_{50}$ were calculated using the probit regression analysis. The values represent the lethal concentration of $T$. indica pulp extract that could kill or induce malformation in half $(50 \%)$ of the population within the period of exposure. After the analysis, the results revealed that the values of $\mathrm{LC}_{50}$ decreased while values for $\mathrm{EC}_{50}$ increased as the zebrafish eggs and larvae are exposed to longer periods of $T$. indica pulp extract

After different periods of exposure, the estimated $\mathrm{LC}_{50}$ values for $24 \mathrm{~h}, 48 \mathrm{~h}$ and $72 \mathrm{~h}$ were $1455 \mathrm{mg} / \mathrm{L}$, $1023 \mathrm{mg} / \mathrm{L}$ and $801 \mathrm{mg} / \mathrm{L}$, respectively. This decreasing trend of $\mathrm{LC}_{50}$ values suggests that $T$. indica pulp extract increases its ability to induce toxicity relative to exposure time; the toxicity of a chemical or substance increases as the value of $\mathrm{LC}_{50}$ decreases (Karasu and Köksal, 2005). Therefore, the extract is not toxic at 24 and $48 \mathrm{~h}$ of exposure as $\mathrm{LC}_{50}$ for these time points $(1455 \mathrm{mg} / \mathrm{L})$ were higher than $1000 \mathrm{mg} / \mathrm{L}$ while $T$. indica pulp extract at $801 \mathrm{mg} / \mathrm{L}$ after $72 \mathrm{~h}$ of exposure could be considered as medium toxic. This is in accordance with Clarkson's toxicity index that classifies plant extracts based on $\mathrm{LC}_{50} . \mathrm{LC}_{50}$ above $1000 \mu \mathrm{g} / \mathrm{ml}$ are non-toxic, $\mathrm{LC}_{50}$ of $500-1000 \mu \mathrm{g} / \mathrm{ml}$ are low toxic, extracts with $\mathrm{LC}_{50}$ of $100-500 \mu \mathrm{g} / \mathrm{ml}$ are medium toxic, while extracts with $\mathrm{LC}_{50}$ of $0-100 \mu \mathrm{g} / \mathrm{ml}$ are highly toxic (Clarkson et al., 2004).

The medium toxicity of $T$. indica pulp extract only shows the nature of the tamarind pulp as a nutraceutical; a widely consumed plant that possesses a rich source of minerals as reported by Parvez et al. (2003). From the study of Jimoh and Onabanjo, (2012), presence of some toxic elements 
was detected in the content analysis of the tamarind pulp, yet it was revealed that contents of these elements were relatively low and safe for consumption. Hence, the results of the $\mathrm{LC}_{50}$ values at different time points, suggests the embryotoxic potential of $T$. indica pulp extract maximizes with respect to the period of exposure and level of concentration of the extract.

Considering the estimated values of $\mathrm{EC}_{50}$, the results suggest that the ability of $T$. indica pulp extract to affect the morphological structure of a developing embryo occurs only in lower concentrations of the extract and this presumption is also in line with the observations from previous studies. The occurrence of malformations in low concentrations in zebrafish embryos at $48 \mathrm{hpf}$ exposed to L. tigrinus extract $(0.5 \%)$ revealed a serious edema in the pericardial sac which was not observed in higher concentrations (Dulay et al., 2012). Moreover, a research on the influence of the aqueous leaf extract of $F$. glomerarata on the zebrafish embryos reported similar observations in which malformations such as yolk sac edema, scoliosis or flexure, and abnormal head-trunk angle were occurring at 250 and 500 $\mathrm{mg} / \mathrm{L}$ - lower concentrations of the extract (Shaikh et al., 2019).

The degree of malformation that was observed in lower concentrations of $T$. indica pulp extract may be attributed to the altered physiological response of the exposed embryos to the extract or the level of solubility of the extract to penetrate the protective membrane of the embryos, the chorion. Malformations in the morphology of the developing zebrafish were often identified during the late stages of its development or after the prolonged exposure of the test organism to the extract $(72 \mathrm{~h})$. Within this period, larvae are hatched outside the chorion and are at a critical stage of embryogenesis (van Leeuwen et al., 1985; Kimmel et al., 1995). Hence, leads us to focus on the altered-response approach; suggests that at lower concentrations, $T$. indica pulp extract's potency was enough to successfully cause a disturbance in the innate response of the developing embryo and thus, the formation of the structural deformities.

Although malformations on exposed embryos were observed at the earliest observatory timepoint (24 hpf), the number of the occurring malformations at the last time point ( $72 \mathrm{hpf}$ ) extensively increased where the critical process of embryogenesis occurs. Therefore, this study argues that $T$. indica pulp extract may only effectively induce malformations after its prolonged exposure (after $72 \mathrm{~h}$ or more) to the zebrafish larvae.

TI scores are often used to classify substances with teratogenic potential and the higher the TI score, the higher possibility of the substance to produce teratogenic effects (Fabro et al., 1982; Selderslaghs et al., 2009). The TI score for T. indica pulp extract at 24 hpf was 3.73, a score above the standard $(\mathrm{TI}>1)$, enough to claim the pulp extract's teratogenic potential at this time point. However, the TI score at $24 \mathrm{hpf}$ cannot be exclusively used to formulate an assumption about $T$. indica pulp extract's teratogenicity; on the earliest period of exposure. Since the calculated TI values of a substance also reflects the extensive gap between the toxicity and malformation in concentration-response curves. It is possible that there is an agent (i.e. plant extract or toxicant) that's more likely to cause serious malformations than to promote death; conversely, a potential toxicant can be so lethal that morphological deformities cannot be expressed (Reimers et al., 2004).

One factor to consider in supporting $T$. indica pulp extract's nature to be concentration-dependent is the increased sensitivity of the developing zebrafish embryos to external exposure to any substances or compounds. The inherent nature of the eggs to develop defense mechanisms are still on the process of completion, and thus, exposed eggs are least expected to possess the complete ability to expel exogenous substances that may accordingly affect other ongoing embryonic processes (Lahnsteiner et al., 2001). Also, dependency of the embryotoxic and teratogenic effects of $T$. indica pulp extract to levels of concentration with respect to time could also be explained as the accumulation of the extract through time enough to penetrate through the chorion's membrane and induce toxicity or deformity to a developing embryo. In addition, a second consideration is the intrinsic toxicity of the substance tested. Toxins that are normally present in the substance can induce inhibition to specific route of toxicity and when exposed to susceptible individuals, exhibit toxic responses - death or morphological deformity. Thus, toxic substances affect normal development of embryos and larvae by specific inhibitory activities rather than the general malfunction in embryonic processes (Hallare et al., 2014). 


\section{Conclusion}

The study successfully investigated the ability of $T$. indica pulp extract to elicit toxicity and teratogenic effects on zebrafish embryos and larvae. Most mortality were observed at higher concentrations indicating that the pulp extract can cause acute toxicity following a concentration-dependent manner. In contrast, incidences of malformation dramatically increased at $72 \mathrm{hpf}$, specifically in lower levels of $T$. indica pulp extract concentration where teratogenic index revealed malformations to the exposed larvae. This study argues that investigation on the embryotoxic and teratogenic effects of the $T$. indica pulp extract should be considered as two independent features of the plant's toxicity; since embryotoxicity of $T$. indica pulp extract manifests in high doses of concentration and its teratogenicity in lower concentrations. Furthermore, this study reports additional data on the toxicity of $T$. indica using the pulp extract apart from previous studies using the leaves and stem bark.

\section{Acknowledgement}

This research would not have been possible without the generous guidance and assistance of the Cebu Normal University-Research Institute of Tropical Biology and Pharmacological Biotechnology (CNURITBPB) and Biology Department of the College of Arts and Sciences, Cebu Normal University. We thank the anonymous reviewers for their careful reading of our manuscript and their many insightful comments and suggestions.

\section{Disclaimer: None.}

Conflict of Interest: None.

Source of Funding: None.

\section{References}

Abubakar MG, Ukwuani AN and Shehu RA, 2008. Phytochemical screening and antibacterial activity of Tamarind (Tamarindus indica) pulp extract. Asian J. Biochem. 3(2): 134-138.

Adedayo MR, Babatunde SK, Ajiboye AE and Habeeb LM, 2016. Antimycotic and phytochemical screening of the fruit pulp extract of tamarind (Tamarindus indica) on Candida albicans. J. Microbiol. Antimicrob. Agents. 2(1): 16-21.
Adeniyi OV, Olaifa FE, Emikpe BO and Ogunbanwo ST, 2017. Phytochemical components and antibacterial activity of Tamarindus indica Linn. Extracts against some pathogens. Biotechnol. J. Int. 17(2): 1-9.

Aida P, Rosa V, Blamea F, Tomas A and Salvador C, 2001. Antifungal activity of Paraguayan plants used in traditional medicine. J. Ethnopharmacol. 76(1): 93-98.

Alafiatayo AA, Lai KS, Syahida A, Mahmood M and Shaharuddin NA, 2019. Phytochemical evaluation, embryotoxicity, and teratogenic effects of Curcuma longa extract on zebrafish (Danio rerio). Evidence-Based Complement. Altern. Med. 1-10.

Ali S, Khan MR, Irfanullah SM and Zahra Z, 2018. Phytochemical investigation and antimicrobial appraisal of Parrotiopsis jacquemontiana (Decne) Rehder. BMC Complement. Altern. Med. 18(1): 43.

Ali S, Mil HGJv and Richardson MK, 2011. Largescale assessment of the zebrafish embryo as a possible predictive model in toxicity testing. PLoS One. 6(6): e21076.

Al-Nuaimi AAHD, 2018. Extracts of plants used as traditional medicines have toxic effect on the liver and kidney. Moj. Anat. Physiol. 5(1): 32-41.

Akintonwa A, Awodele O, Afolayan G and Coker HA, 2009. Mutagenic screening of commonly used medicinal plants in Nigeria. J. Ethnopharmacol. 125(3): 461-470.

Andreicut AD, Pârvu AE, Mot AC, Pârvu M, Fischer-Fodor E, Cătoi AF, Feldrihan V, Cecan $\mathrm{M}$ and Trimie A, 2018. Phytochemical analysis of anti-inflammatory and antioxidant effects of Mahonia aquifolium flower and fruit extracts. Oxid. Med. Cell Longev. 2018: 1-12.

Anu, Das MP and Banerjee A, 2014. Extraction of tamarind pulp and its antibacterial property. Asian J. Plant Sci. Res. 4(2): 47-49.

Apu A, Chowdhury F, Khatun F, Jamaluddin A, Pathan A and Pal A, 2013. Phytochemical screening and in vitro evaluation of pharmacological activities of Aphanamixis polystachya (Wall) parker fruit extracts. Trop. J. Pharma. Res. 12(1): 111.

Asase A, Oteng-Yeboah AA, Odamtten GT and Simmonds MSJ, 2005. Ethnobotanical study of some Ghanaian antimalarial plants. J. Ethnopharmacol. 99(2): 273-279. 
Avdesh A, Chen M, Martin-Iverson M, Mondal A, Ong D, Rainey-Smith S, Taddei K, Lardelli M, Groth D, Verdile G and Martins R, 2012. Regular care and maintenance of a zebrafish (Danio rerio) laboratory: An Introduction. J. Visualized Exp. (69): e4196

Brannen KC, Panzica- Kelly JM, Danberry TL and Augustine- Rauch KA, 2010. Development of a zebrafish embryo teratogenicity assay and quantitative prediction model. Birth Defects Research Part B: Devel. Reprod. Toxicol. 89(1), 66-77.

Caspi R, Billington R, Fulcher CA, Keseler IM, Kothari A, Krummenacker M and Karp PD, 2017. The MetaCyc database of metabolic pathways and enzymes. Nucleic Acids Res. 46(D1): D633-D639.

Clarkson C, Maharaj VJ, Crouch NR, Grace O M, Pillay P, Matsabisa MG, Bhagwandin N, Smith PJ and Folb PI, 2004. In vitro antiplasmodial activity of medicinal plants native to or naturalized in South Africa. J. Ethnopharmacol. 92(2-3): 177-191.

Consuegra CRD, Custodio FMB, Pananganan JPL, Ramirez WJD, Garces JJC, and Picardal JP, 2020. Teratogenicity and Acute Toxicity of Selected Philippine Indigenous Spices Using Brine Shrimp Lethality Assay and Zebrafish Assay . .105-Pharmacophore. 11(4): 88

Costa K, Bezerra S, Norte C, Nunes L and Olinda T, 2012. Medicinal plants with teratogenic potential: current considerations. Braz. J. Pharm Sci. 48(3): 427-433.

Deepak KD, Bibekananda M and Anupam R, 2014. A review on: Phytochemistry, pharmacology and traditional uses of Tamarindus indica L. World J. Pharm. Pharm. Sci. 3(10): 229-240.

De Vera JS, De Castro MEG and Dulay RM, 2016. Phytochemical screening and teratogenic effect of lyophilized water extracts from Ocimum sanctum L. (Holy Basil) and Tamarindus indica L. (Tamarind) leaves in Danio rerio embryos. Der. Pharma. Chemica. 8(8): 86-91.

Dubińska-Magiera M, Daczewska M, Lewicka A, Migocka-Patrzałek M, Niedbalska-Tarnowska J and Jagla K, 2016. Zebrafish: A model for the study of toxicants affecting muscle development and function. Int. J. Mol. Sci. 17(11).

Dulay RMR, Kalaw SP, Reyes RG, Cabrera E and Alfonso N, 2012. Optimization of culture conditions for mycelial growth and basidiocarp production of Lentinus tigrinus (Bull) Fr., A new record of domesticated wild edible Mushroom in the Philippines. Philipp. Agric. Sci. 95(3): 278285.

Fabro S, Shull G and Brown N, 1982. The relative teratogenic index and teratogenic potency: Proposed components of developmental toxicity risk assessment. Teratogenesis, Carcinogenesis and Mutagenesis. 2(1): 61-76.

Fraysse B, Mons R and Garric J, 2006. Development of a zebrafish 4-day embryo-larval bioassay to assess toxicity of chemicals. Ecotoxicol. Environ. Saf. 63(2), 253-267.

Finney DJ, 1952. Probit analysis: a statistical treatment of the sigmoid response curve. Cambridge university press, Cambridge.

Green M, Lebron J, Tanis K, Redfern B, Zhu L, Yu Y, Wang E, Kaczor A, Wysoczanski E, Chen F, Raymond C, Mattson B, Sistare F and Degeorge J, 2018. Use of alternative developmental toxicity assays to assess teratogenicity potential of pharmaceuticals. Appl. In Vitro Toxicol. 4(1): 44-53.

Gilbert-Barness E, 2010. Teratogenic causes of malformations. Ann. Clin. Lab. Sci. 40(2), 99114.

Haldi M, Harden M, D'Amico L, DeLise A and Seng WL, 2011. Developmental toxicity assessment in zebrafish. In Zebrafish: Methods for Assessing Drug Safety and Toxicity. pp. 15-25.

Halili J and Quilang J, 2011. The zebrafish embryo toxicity and teratogenicity assay. The zebrafish embryo toxicity and teratogenicity assay. The Philippine Biota. 63-71.

Hallare A, Kohler HR and Triebskorn R, 2004. Developmental toxicity and stress protein responses in zebrafish embryos after exposure to diclofenac and its solvent, DMSO. Chemosphere. 56(7): 659-666.

Hallare A, Ruiz P and Cariño J, 2014. Assessment of Jatropha curcas L. biodiesel seed cake toxicity using the zebrafish (Danio rerio) embryo toxicity (ZFET) test. Environ. Sci. Pollut. Res Int. 21(9): 6044-6056.

Havsteen BH, 2002. The Biochemistry and medical significance of the flavonoids. Pharmacol. Ther. J. 96(2-3): 67-202.

Heger S, Bluhm K, Agler MT, Maletz S, Schäffer A, Seiler TB, Angenent LT and Hollert H, 2012. Biotests for hazard assessment of biofuel fermentation. Energy Environ. Sci. 5: 9778- 
9788.

Hodek P, Trefil P and Stiborová M, 2002. Flavonoids-potent and versatile biologically active compounds interacting with cytochromes P450. Chem. Biol. Interact. 139(1): 1-21.

Jimoh SO and Onabanjo OO, 2012. Potentials of Tamarindus indica (Linn.) in jam production. J. Agric. Soc. Res. 12(2): 29-43.

Kanki JP and Ho RK, 1997. The development of the posterior body in zebrafish. Development. 124(4): 881-893.

Karasu B and Köksal G, 2005. The acute toxicity of ammonia on tilapia (Oreochromis niloticus L.) larvae and fingerlings. Turk. J. Vet. Anim. Sci. 29(2): 339-344.

Khalid S, Mossadeq WS, Israf DA, Hashim P, Rejab S, Shaberi AM and Sulaiman MR, 2010. In vivo analgesic effect of aqueous extract of Tamarindus indica L. fruits. Med. Princ. Pract. 19(4): 255259.

Khan I, Kant C, Sanwaria A and Meena L, 2010. Acute cardiac toxicity of Nerium oleander/indicum poisoning (kaner) poisoning. Heart views: The Official J. Gulf Heart Assoc. 11(3): 115-116.

Khanzada SK, Shaikh W, Sofia S, Kazi TG, Usmanghani K, Kabir A and Sheerazi TH, 2008. chemical constituents of Tamarindus indica L. medicinal plant in Sindh. Pak. J. Bot. 40(6): 2553-2559.

Kimmel C, Ballard W, Kimmel S, Ullmann B and Schilling T, 1995. Stages of embryonic development of the zebrafish. Dev. Dyn. 203(3): 253-310.

Kuru P, 2014. Tamarindus indica and its health related effects. Asian Pac. J. Trop. Biomed. 4(9): 676-681.

Lahnsteiner F, Urbanyi B, Horvath A and Weismann $\mathrm{T}$, 2001. Bio-markers for egg quality determination in cyprinid fish. Aquaculture. 195(3-4): 331-352.

Lantz- McPeak S, Guo X, Cuevas E, Dumas M, Newport GD, Ali SF and Kanungo J, 2015. Developmental toxicity assay using high content screening of zebrafish embryos. J. Appl. Toxicol. 35(3), 261-272.

Li J, Hubbard P and Canário A, 2018. Male zebrafish (Danio rerio) odorants attract females and induce spawning. Aquac. Fisheries. 3(4): 139-144.

Matthews M and Varga Z, 2012. Anesthesia and Euthanasia in Zebrafish. ILAR Journal. 53(2):
192-204.

Mujeeb F, Bajpai $\mathrm{P}$ and Pathak N, 2014. Phytochemical evaluation, antimicrobial activity, and determination of bioactive components from leaves of Aegle marmelos. BioMed Res. Int. 2014: 497606.

Mullins MC, Hammerschmidt M, Kane DA, Odenthal J, Brand M, van Eeden FJ, FurutaniSeiki M, Granato M, Haffter P and Heisenberg CP, 1996. Genes establishing dorsoventral pattern formation in the zebrafish embryo: the ventral specifying genes. Development. 123: 8193.

Ong KJ, Felix LC, Boyle D, Ede JD, Ma G, Veinot JGC and Goss GG, 2017. Humic acid ameliorates nanoparticle-induced developmental toxicity in zebrafish. Environ. Sci: Nano. 4(1): 127-137.

Nwodo U, Obiiyeke GE, Chigor VN and Okoh AI, 2011. Assessment of Tamarindus indica extracts for antibacterial activity. Int. J. Mol. Sci. 12(10): 6385-6396.

Nwodo UU, Ngene AA, Anaga AO, Chigor VN, Henrietta II and Okoh AI, 2011. Acute toxicity and hepatotoxicokinetic studies of Tamarindus indica extract. Molecules. 16(9): 7415-7427.

Parvez SS, Parvez MM, Fujii Y and Gemma H, 2003. Allelopathic competence of Tamarindus indica L. root involved in plant growth regulation. Plant Growth Regulation. 41(2): 139148.

Pimple BP, Kadam PV, Badgujar NS, Bafna AR and Patil MJ, 2007. Protective effect of Tamarindus indica Linn. against paracetamol-induced hepatotoxicity in rats. Indian J. Pharma Sci. 69(6): 827.

Rajagopal R, Balasubramanian $\mathrm{M}$ and Kalyanaraman S, 2017. Raw Turmeric and Pure curcumin: A Comparison of Embryonic Cytotoxicity in Zebrafish. Int. J. Basic \& Clin. Pharmacol. 6(8): 2020-2026.

Reimers MJ, Flockton AR and Tanguay RL, 2004. Ethanol- and acetaldehyde-mediated developmental toxicity in zebrafish. Neurotoxicol. Teratol. 26(6): 769-781.

Roy MG, Rahman S, Rehana F, Munmun M, Sharmin N, Hasan Z and Rahmatullah M, 2010. Evaluation of anti-hyperglycemic potential of methanolic extract of Tamarindus indica $\mathrm{L}$. (Fabaceae) fruits and seeds in glucose-induced hyperglycemic mice. Adv. Nat. Appl. Sci. 4(2): 159-162. 
Irish C. Lobitaña et al.

Schneider A, Hommel G and Blettner M, 2010. Linear regression analysis: part 14 of a series on evaluation of scientific publications. Dtsch. Arztebl. Int. 107(44): 776-782.

Selderslaghs I, Van Rompay A, De Coen W and Witters H, 2009. Development of a screening assay to identify teratogenic and embryotoxic chemicals using the zebrafish embryo. Reprod. Toxicol. 28(3): 308-320.

Shaikh A, Kohale K, Ibrahim M and Khan M, 2019. Teratogenic effects of aqueous extract of Ficus glomerata leaf during embryonic development in zebrafish (Danio rerio). J. Appl. Pharma. Sci. 9(5): 107-111.

Shu Y, Cao M, Yin Z, Li P, Li T, Long X, Zhu LF, Jia RY, Dai SJ and Zhao J, 2015. The reproductive toxicity of saponins isolated from cortex albiziae in female mice. Chin. J. Nat. Medicines. 13(2): 119-126.

Singleman C and Holtzman NG, 2014. Growth and maturation in the zebrafish, Danio rerio: a staging tool for teaching and research. Zebrafish. 11(4): 396-406.

Sorrentino RP, 2010. Large standard deviations and logarithmic-normality: the truth about hemocyte counts in Drosophila. Fly (Austin). 4(4): 327332.

Truong L, Harper S and Tanguay R, 2011. Evaluation of Embryotoxicity Using the zebrafish model. Method. Mol. Biol. 271-279.

Ushanandini S, Nagaraju S, Kumar KH, Vedavathi M, Machiah DK, Kemparaju K, Vishwanath BS, Gowda TV and Girish KS, 2006. The antisnake venom properties of Tamarindus indica (Leguminosae) seed extract. Phytother. Res. 20(10): 851 858. https://doi.org/10.1002/ptr.1951

Van den Bulck K, Hill A, Mesens N, Diekman H, De Schaepdrijver L and Lammens L, 2011. Zebrafish developmental toxicity assay: a fishy solution to reproductive toxicity screening, or just a red herring? Reprod. Toxicol. 32(2), 213-219.

van Leeuwen CJ, Maas-Diepeveen J, Niebeek G, Vergouw W, Griffioen P and Luijken M, 1985. Aquatic toxicological aspects of dithiocarbamates and related compounds. Aquat. Toxicol. 7(3): 145-164.

Vyas N, Gavatia NP, Gupta B and Tailing M, 2009. Antioxidant potential of Tamarindus indica seed coant. J. Pharm. Res. 2(11): 1705-1706.

Westerfield M, 2000. The Zebrafish Book. A Guide for the Laboratory use of Zebrafish (Danio rerio)4th edition. Eugene, University of Oregon Press. Xia Q, Ma Z, Mei X, Luo J, Wang Y, Li T, Feng Y, Ni Y, Zou Q and Lin R, 2017. Assay for the developmental toxicity of safflower (Carthamus tinctorius L.) to zebrafish embryos/larvae. J. of Tradit. Chin. Med. Sci. 4(1): 71-81.

\section{Contribution of Authors}

Lobitaña IC: Conceived idea, literature review, designed research methodology, supervised lab work, data collection and analysis and manuscript writing

Virtudazo RME: Designed research methodology, lab work, data collection data analysis Delfin AMP: Designed research methodology, data collection and analysis lab work Apura JNB: Designed research methodology, data collection and analysis lab work

Picardal JP: Literature review, data interpretation, manuscript final reading and approval Garces JJC: Designed research, literature review, data interpretation, helped in article write up, manuscript final reading and approval 